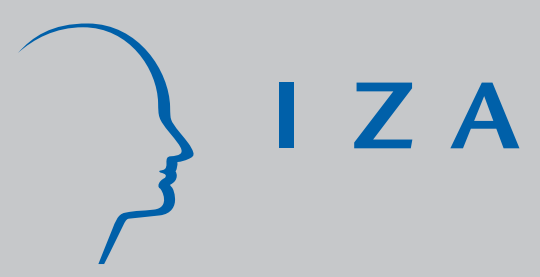

IZA DP No. 2295

Assessing the Effect of Mother's Migration on Childhood Mortality in the Informal Settlements of Nairobi

Adama Konseiga

Eliya Msiyaphazi Zulu

Yazoumé Yé

September 2006 


\title{
Assessing the Effect of Mother's Migration on Childhood Mortality in the Informal Settlements of Nairobi
}

\author{
Adama Konseiga \\ African Population and Health Research Center (APHRC) \\ and IZA Bonn \\ Eliya Msiyaphazi Zulu \\ African Population and Health Research Center (APHRC) \\ Yazoumé Yé \\ African Population and Health Research Center (APHRC)
}

Discussion Paper No. 2295

September 2006

\author{
IZA \\ P.O. Box 7240 \\ 53072 Bonn \\ Germany \\ Phone: +49-228-3894-0 \\ Fax: +49-228-3894-180 \\ Email: iza@iza.org
}

\begin{abstract}
Any opinions expressed here are those of the author(s) and not those of the institute. Research disseminated by IZA may include views on policy, but the institute itself takes no institutional policy positions.
\end{abstract}

The Institute for the Study of Labor (IZA) in Bonn is a local and virtual international research center and a place of communication between science, politics and business. IZA is an independent nonprofit company supported by Deutsche Post World Net. The center is associated with the University of Bonn and offers a stimulating research environment through its research networks, research support, and visitors and doctoral programs. IZA engages in (i) original and internationally competitive research in all fields of labor economics, (ii) development of policy concepts, and (iii) dissemination of research results and concepts to the interested public.

IZA Discussion Papers often represent preliminary work and are circulated to encourage discussion. Citation of such a paper should account for its provisional character. A revised version may be available directly from the author. 


\section{ABSTRACT \\ Assessing the Effect of Mother's Migration on Childhood Mortality in the Informal Settlements of Nairobi}

Between one and two million migrants reside in cramped conditions in Nairobi's slums without proper access to sanitation or affordable clean water. Children in such areas are exposed to enormous risks, health risks in particular. Using longitudinal data collected every four months during the period between 2002 and 2004, we analyze their survival patterns of children under five year of age who resided in two informal settlements (Viwandani and Korogocho). The research question assumes that children born to recent migrant mothers are more likely to die. The assumption is that migrant mothers do not have social network, which translates to a lack of information and lower access to health facilities. In the subsequent event history analysis, childhood mortality is shown to remain very high in the Nairobi informal settlements, especially among new migrants. Given the high degree of rural urban migration, which is bound to increase in the foreseeable future for most African countries, our study raises critical public health concerns. Another important finding in the context of the HIV AIDS pandemic is the risk factor associated to the mortality among children who have lost their mother. Our study also demonstrated a persistent disadvantage of children born to migrant mothers irrespective the length of stay in the receiving zone. The latter seems to point out the difficulties for migrant to develop social network outside their area of origin.

JEL Classification: C24, C41, I12, R23

Keywords: migration, informal settlements, childhood mortality, Nairobi

Corresponding author:

Adama Konseiga

African Population and Health Research Center

Shelter Afrique Building

Longonot Road

P. O. Box 10787

00100 Nairobi

Kenya

E-mail: Akonseiga@aphrc.org 


\section{Background}

In recent decades, there is general agreement that childhood mortality has significantly decreased in most SSA countries. However, the level remains unacceptably high (Delaunay et al. 2001, Garenne \& Gakusi 2006). This situation is partly attributed to the poor socio-economic and political conditions, poor health care system, and poor hygienic and environmental conditions. This pool of conditions favors the proliferation of the major killers such as malaria, pneumonia, diarrhea and other infectious diseases (WHO 2006).

The global picture of childhood mortality in SSA hides differences between regions, countries, socio-economic groups and rural-urban dwellers. Indeed, Garenne \& Gakusi, 2006, found that the decrease of under-five mortality is not homogeneous for the 66 African countries included in their analysis over a 50-year period. Some of these countries had even observed periods of increase in mortality due to political and economic crises. The most commonly reported mortality differences are those between rural and urban dwellers, and between the rich and poor as measured by wealth quintiles (Panel on Urban Population Dynamics 2003). Children living in rural areas experience high mortality compared to their counterparts in urban settings. A number of studies have

demonstrated this urban advantage in terms of childhood mortality and this is mainly explained by better access to health care services including preventive and curative. An analysis of DHS data from several African countries comparing rural and urban areas using height and weight as a measure of children's health status found that on average urban children were healthier than rural ones (Panel on Urban Population Dynamics 2003). However, a more detailed analysis revealed that social economic status was the major driver of this differences rather than the place for residence. Using wealth quintiles, they demonstrated that children from poor urban households experienced about the same health status as their rural counterparts. In Kenya between one and two million migrants reside in cramped conditions in Nairobi's slums without proper access to sanitation or affordable clean water. Children in such areas are exposed to enormous risks, health risks in particular. For example, a large demographic and health focused survey conducted in various Nairobi slums in 2002 by the African Population and Health Research Center (APHRC) finds that not only are morbidity risks for all major childhood illnesses (fever, cough, diarrhea) higher for slum children compared to children elsewhere in Kenya, slum children also have less access to healthcare, including immunization, and subsequently face higher mortality rates than even their rural counterparts. For instance, APHRC reports that infant, child, and under 5 mortality rates are about 20,65, and 35 percent, respectively, higher in the slum communities of Nairobi compared to rural Kenya while incidence of common childhood illnesses are two to three times higher in the slums relative to rural areas.

A clear health status difference was observed between urban poor and urban non-poor with a significant advantage of non- poor. These findings confirmed the clear mortality advantage of urban children compared to the rural ones, but also highlighted the difference between the urban poor and non poor. The protective effect of the urban 
setting is therefore distorted by the social economic status. Poor urban children experience higher mortality compared to the rich urban ones partly due to the former's poor access to health care, poor nutrition and poor housing conditions (Songsore 2000). The rapid and uncontrolled growth of African cities has forced the poor to live in informal settlements characterized by poor access to water supply and sanitation, poor and crowded housing, insect and rat infestation, garbage disposal and nonexistence drainage system - conditions that are know to indirectly affect their health. In addition, they are exposed to air pollution, water pollution and other factors which indirectly affect their health (Smith and lee 1993, McGranahan and Songsore 1994). An estimated 30$60 \%$ of urban populations in Africa live in slums and squatter settlements (UNCHS/Habitat 1992). As a result, in every urban setting many people live in neighborhoods with little or no infrastructure, social services or facilities that are essential for good health (Songsore 2000). The rapid growth of African cities is partly attributable to the natural increase within the town, but mainly to migration from ruralsettings. African urbanization is therefore considered a demographic urbanization rather than economic urbanization (Escalier 1988, Clark 1993, Gould 1998).

Rural populations migrating to urban settings in search of better opportunities face the same challenges described above. Apart from the fact that they have to adapt to new realities, they have to deal with the same health challenges as established residents. This situation may impact on their health status depending on how fast they integrate into the new settings. The most vulnerable in this case are the children who follow their parents/caretakers since they are faced with new living and nutrition conditions. There are few documented studies that have looked at the health conditions on these newly migrated children in their new setting in relation to their place of origin. Existing studies are based on a cross-sectional data but these have limitations since they do not account for time changing circumstances that may impact on health.

A study in Ethiopia observed that children from migrant mother (rural-urban) had lower immunisation coverage compared to those from non-migrant mothers (Kiros \& White 2004). Immunization has been extensively reported in the literature as a contributor to the reduction of childhood mortality (Foster 1995, Nyarko et al 2001). We would therefore expect the mortality to be lower among children from non-migrant mothers. In this context the differences in utilization could be attributed to poor social networks and poor integration into the host communities of migrant mothers. This led to their lack of information about the availability, quality and experiences with the health services. These differences were not affected by the duration of residence of the migrant mother suggesting that integration and acceptance into the host society was more important than the length of stay. The study by Kiros \& White 2004 was however conducted in a particular cultural context and so the length of stay may be relevant in a different context. One would expect that in coming mothers gradually become aware of the available health care services and other health related information (Kiros \& White 2004).

There is little information about the impact of the migration of adult caretakers on the health of their accompanying children especially in situations of rural-urban migration where they are more likely to move from a bad to worse environment. The NUHDSS 
offers an ideal setting to answer the question of whether the migration of a mother has an impact of the health of the child. In this setting it is possible to monitor the migration status of the mother, their duration of stay in the DSA and the health status of the child. We therefore elected to assess whether the migration status of the mother had an effect on the health of their children using mortality as a proxy for health status.

\section{Objectives}

We seek to address the following objectives:

- To describe childhood mortality patterns in two urban informal settlements in Nairobi

- To assess the effect of mothers' migration on childhood mortality in urban informal settlements

\section{Methods}

\section{Study site}

The Nairobi Urban Health and Demographic Surveillance System (NUHDSS), which is implemented by the African Population and Health Research Center (APHRC), covers a Demographic Surveillance Area (DSA) that straddles the two slums of Korogocho and Viwandani in Nairobi city, Kenya. Both are informal settlements located about 5-10 km from the city centre and $3 \mathrm{~km}$ from each other. Nairobi is the capital and commercial centre of Kenya with a population of about three million (CBS, 2006). Although Nairobi is only $145 \mathrm{~km}$ (1.5 degrees) south of the equator, it has a moderate tropical climate, because of its high altitude of about $1,700 \mathrm{~m}$ above sea level. The average day-time temperature varies only slightly throughout the year, from $29^{\circ} \mathrm{C}$ in the dry season and $24^{\circ} \mathrm{C}$ during the rest of the year. At night, however, the temperature sometimes drops to as low as $9^{\circ} \mathrm{C}$.

Being an urban informal settlement, the population under surveillance is highly mobile with an attrition rate of 24\%. The population under surveillance in 2004 was 59698, with 26533 living in Korogocho and 33165 in Viwandani. Each of the two settlements is comprised of seven villages. The residents are from over 15 ethnic backgrounds with the majority being Kikuyu (28\%), Luhya (24\%), Kamba (21\%) and Luo (15\%). Under-five year children represents $15 \%$ of the total population and women in reproductive age (1549 years) constitute $26 \%$. The two study populations vary widely in a number of aspects. In Viwandani, the population is mainly comprised of labor migrants working in the neighboring industrial area, while the Korogocho population is mainly comprised of long-term settlers mostly engaged in the informal sector. Slum settlements are characterized by relatively high crime rates, drug and alcohol abuse, risky sexual behaviors, unemployment rates, and low school participation compared to other urban residents as well as their rural counterparts (APHRC, 2002b; Zulu et al. 2002; Dodoo et al. 2002; Mugisha et al. 2003; Amuyunzu-Nyamongo and Ezeh 2005; Zulu et al. 2006). Compared to the rest of Kenya, the informal settlement exhibit worse health indicators, especially for the under five population (APHRC, 2002b; Taffa, 2003; Magadi et al. 
2003). Poor environmental sanitation is the hallmark of these communities; toilet coverage is very low (1.6\% have access to their own toilet.), there are no sewers or drainage systems and there is limited access to safe drinking water (APHRC 2002a; Amuyunzu-Nyamongo and Taffa, 2004). Houses characteristically have no ventilation and are very overcrowded. These conditions impact dramatically on childhood mortality.

\section{Study population}

Our population of interest is the children under five year of age who resided in the two informal settlements (Viwandani and Korogocho) from the period of 01.08.2002 to 31.12.2004. This includes a study population of 8007 individuals, which represent a 14\% of the total population.

\section{Data collection}

The data was extracted from the DSS data. This implies that the data collection procedures are the ones from the DSS. These procedures include visits to all households in the DSA every four month to update information on all vital events (birth, deaths, movement, vaccination and pregnancy). Movements that are monitored include change of residence and migrations. The 31 fieldworkers are each allocated an enumeration area and their work is regularly checked by seven team leaders, responsible for ensuring the quality of the data collected. Team leaders performed a spot check on $5 \%$ of randomly selected households. Apart from team leaders we have 2 field supervisors who are responsible for the overall data quality. A field coordinator ensures the link between the field and the office (office supervisor, database manager and 13 data entry clerks).

\section{Data management and processing}

Data is processed and managed just like the other data collected from the DSS. There are 13 staff members involved in data entry with minimum training of form four (secondary school) and training in information technology or secretarial services. Currently the data is entered in an SQL database before they are coded. Initially the FoxPro system was used but this was stopped in 2005.

The study data cover the period started at the initial census (between August 1 and September 30, 2002 in Round 0) until December 31, 2004 (Round 7). The population under observation is confined to all under-five children who reside or ever resided in the two slums of Korogocho and Viwandani during the study period.

The NUHDSS offers very rich information for event history analysis as unlike retrospective survey that covers a life time history, the DSS has a very short time band width of follow-up and is able to collect exact date of occurrence for most events of interest. The DSS deals quite well with problems of truncated intervals by asking details about events that occurs since the previous round.

The data table that constitutes the basis for the current study records all information on individuals at a particular physical location in the DSA. The start events and their dates of occurrence give all information related to enumeration, birth or in-migrations while entry into a new location signals start of a new residency spell (change of residence). We appended the end events and their related dates of occurrence to create 'Period 
observation' data appropriate for longitudinal data analysis. Individuals exit the DSA through death or out-migration while those who still reside at the end of the observation period have open residency episode. The end of a residency episode is captured through an exit event (change of residence).

For the multivariate analysis, data on residency episodes are complemented with individual level fixed covariates that summarize the itinerary prior to inclusion in the DSS. The variables are gender, birth cohort, ethnicity, as well as education attainment at the time of entry to DSA. Additional information includes membership status such as individual's relationship to the household head. All characteristics of mothers living in the DSA were also related to the under-five children.

\section{Statistical analysis}

The research question assumes that children born to recent migrant mother are more likely to die. This is captured through the duration of stay of mother or mother's migration status. The assumption is that migrant mothers do not have social network, which translates to a lack of information and lower access to health facilities.

In the following event history analysis, the outcome of interest is the overall survival of under five children in the two informal settlements. We therefore used a Cox proportional hazards model to assess the relative effect of the migration status (migrant or non migrant) of the mothers on childhood survival rates (Klein \& Moeschberger 1997, Valsecchi et al 1996). In addition, we also investigated the effect of mother's length of stay in the slums and a number of socio-demographic factors. The effect of each parameter was expressed as rate ratios. For each child under-five the observation time started either at birth, or enumeration (resident at the beginning of the demographic surveillance, $1^{\text {st }}$ August 2002) or date of in-migration. The observation time ended either at the occurrence of the event of interest (death) or dates of censoring due to refusal or out-migration. The observation time was truncated for all on 31.12.2004. We allowed gaps in the observation time of the individual, meaning that children could out-migrate and come back. All available variables were included in the models. We run four models by progressively including new co-variables, starting with the bivariate effect of mother's migration. We used two sets of variables: those directly related to the child (age, sex, ethnicity and place of residence) and those related to the mothers (age of the mother, whether mother was alive or not, education and length of stay in the slums).

\section{Results}

\section{Study population characteristics}

In total 8,007 under five children participated in the study from 01.08.2002 to 31.12.2004. Out of this total number 3,245 children were from Korogocho and 4,762 from Viwandani. There were no significant differences between the proportions of male (51.47\%) and female (48.53\%). The majority of participants (47.93\%) were aged below one year. The distribution of participants according to the migration status of their mothers shows that the majority of children $(97.30 \%)$ were either born before the mothers migrated in the DSA or were enumerated in the DSA (thereafter called children born to non-migrant mothers or non-migrant born). The proportion of the children born to nonmigrant mothers was higher in Viwandani (59.34\%) compared to Korogocho (40.66\%). 
This pattern is similar and more pronounced in magnitude among the children born to migrant mothers . The sex distribution of children born to migrant mothers (also referred to as migrant born) is different from the non-migrant born. Indeed the proportion of male born to migrant mothers is about $10 \%$ higher than the female, while the difference for non-migrant is less than 3\%. Among both non-migrant and migrant born children the majority is below one year. However, this difference of age is more pronounced among children born to migrant mothers where the under-five ones represent $99.54 \%$, while for the non-migrant born they represent $46.50 \%$ (Table 1 ).

Table 1 The distribution of the study participants according to the migration status of the mothers

\begin{tabular}{|c|c|c|c|c|c|c|c|}
\hline & \multicolumn{2}{|c|}{ Total } & \multicolumn{4}{|c|}{ Children from mother migrated } \\
\hline & & & & Before birth & (\%) & $\begin{array}{l}\text { After birth or } \\
\text { enumerated }\end{array}$ & (\%) \\
\hline $\mathbf{n}$ & & $\mathbf{8 , 0 0 7}$ & & 216 & (2.70) & 7,791 & (97.30) \\
\hline \multicolumn{8}{|c|}{ Site } \\
\hline & Korogocho & 3,245 & (40.53) & 77 & (35.65) & 3,168 & (40.66) \\
\hline & Viwandani & 4,762 & $(59.47)$ & 139 & (64.35) & 4,623 & $(59.34)$ \\
\hline \multicolumn{8}{|c|}{ Gender } \\
\hline & Male & 4,121 & (51.47) & 118 & (54.63) & 4,003 & (51.38) \\
\hline & Female & 3,886 & (48.53) & 97 & (44.91) & 3,789 & $(48.63)$ \\
\hline \multicolumn{8}{|c|}{ Age (Years) } \\
\hline & 0 year & 3,838 & (47.93) & 215 & (99.54) & 3,623 & $(46.50)$ \\
\hline & 1 year & 1,431 & $(17.87)$ & 0 & $(0.00)$ & 1,431 & (18.37) \\
\hline & 2 year & 1,363 & (17.02) & 0 & $(0.00)$ & 1,363 & (17.49) \\
\hline & 3 year & 1,040 & (12.99) & 0 & $(0.00)$ & 1,040 & (13.35) \\
\hline & 4 year & 335 & (4.18) & 0 & $(0.00)$ & 335 & (4.30) \\
\hline
\end{tabular}

\section{Observation}

The observation period was 30 months starting from 01.08.2002 to 31.12.2004. Due to missing information, out of the initial study records $(16,840), 13,411$ subjects were considered for the event history analysis. They were observed for an average of 13.3 months; ranging from 0.03 to 29.01 months. In individual sites, participants were observed for an average of 14.1 months in Korogocho and 12.5 months in Viwandani.

\section{Childhood mortality}

The overall mortality rate was 40.21 per 1000 life births. There is a difference between sites, whereby children in Korogocho experienced higher mortality (63.17 per 1000) than those in Viwandani (23.73 per 1000). Males have significantly higher mortality compared to female (44.89 per 1000 and 35.25 per 1000 respectively). Children less than two years of age experienced higher mortality compared to the older ones. The mortality rates for children under-one and those aged 12-24 months were respectively (55.50 per 1000 and 34.94 per 1000). Very high differences of mortality were observed between non-migrant born and migrant born children. Indeed, the mortality rate for children born to migrant 
mothers is about two times higher than the one from non-migrant born (97.22 per 1000 and 38.63 per 1000 respectively). After stratifying by site, the mortality remains high among children born to migrant mothers compared to those born to non-migrant mothers. In either case the highest mortality was observed among children in Korogocho. Among migrant born children, males had higher mortality than females in both sites and underones had the highest mortality. The rate among children aged 12-24 months in the migrant born could not be determined due to the small number of observed deaths (Table 2).

Table 2 Distribution of the incidence of deaths among study participants

\begin{tabular}{|c|c|c|c|c|c|c|c|c|c|}
\hline \multirow{3}{*}{ Variables } & & & & \multicolumn{6}{|c|}{ Children from mother migrated } \\
\hline & \multicolumn{3}{|c|}{ Total } & \multicolumn{2}{|c|}{ Before birth } & \multicolumn{4}{|c|}{ After birth } \\
\hline & death & $\mathrm{n}$ & $\begin{array}{c}\text { Rate } \\
(1000)\end{array}$ & Death & $\mathrm{n}$ & $\begin{array}{l}\text { Rate } \\
(1000)\end{array}$ & Death & $\mathrm{n}$ & $\begin{array}{c}\text { Rate } \\
(1000)\end{array}$ \\
\hline $\mathrm{n}$ & 322 & 8,007 & 40.21 & 21 & 216 & 97.22 & 301 & 7,791 & 38.63 \\
\hline \multicolumn{10}{|l|}{ Slum } \\
\hline Korogocho & 205 & 3,245 & 63.17 & 13 & 77 & 168.83 & 192 & 3,168 & 60.61 \\
\hline Viwandani & 113 & 4,762 & 23.73 & 8 & 139 & 57.55 & 105 & 4,623 & 22.71 \\
\hline \multicolumn{10}{|l|}{ Gender } \\
\hline Male & 185 & 4,121 & 44.89 & 13 & 118 & 110.17 & 172 & 4,003 & 42.97 \\
\hline Female & 137 & 3,886 & 35.25 & 9 & 97 & 92.78 & 128 & 3,789 & 33.78 \\
\hline \multicolumn{10}{|l|}{ Age (Years) } \\
\hline 0 & 213 & 3,838 & 55.50 & 20 & 215 & 93.02 & 193 & 3,623 & 53.27 \\
\hline 1 & 50 & 1,431 & 34.94 & 1 & 0 & - & 49 & 1,431 & 34.24 \\
\hline 2 & 28 & 1,363 & 20.54 & 0 & 0 & - & 28 & 1,363 & 20.54 \\
\hline 3 & 19 & 1,040 & 18.27 & 0 & 0 & - & 19 & 1,040 & 18.27 \\
\hline 4 & 12 & 335 & 35.82 & 0 & 0 & - & 12 & 335 & 35.82 \\
\hline
\end{tabular}

\section{Childhood survival expressed by Kaplan Meier curve}

\section{Overall survival probability}

After the first year of observation we recorded 274 deaths giving a survival probability of 0.9736 (95\% CI, 0.9703-0.9766). In the following year the number of deaths dropped abruptly and only 35 deaths were observed. The survival probability was estimated at 0.9658 (95\% CI, 0.9614-0.9697). Due to the small number of individuals observed in the third year the survival probability was not calculated (Table 3). More detailed monthly survival probabilities are presented in the Kaplan Meier survival curve (Figure 1). In the first 14 months the survival probability decreased rapidly from 1 to 0.97 . From the $14^{\text {th }}$ month it continues to decrease, however at a lower rate until the end of the last month of observation where the probability remains between 0.96 and 0.97 . This suggests that $96 \%$ of the children survived. 
Table 3 Life table of study participants over the observation period (yearly scale)

\begin{tabular}{|c|c|c|c|c|c|}
\hline $\begin{array}{l}\text { Observation } \\
\text { time (year) }\end{array}$ & $\mathrm{N}$ & Death & $\begin{array}{l}\text { Survival } \\
\text { probability }\end{array}$ & $95 \% \mathrm{CI}$ & \\
\hline Year 1 & 6329 & 274 & 0.9736 & 0.9703 & 0.9766 \\
\hline Year 2 & 2572 & 35 & 0.9658 & 0.9614 & 0.9697 \\
\hline Year 3 & 32 & 7 & & & \\
\hline
\end{tabular}

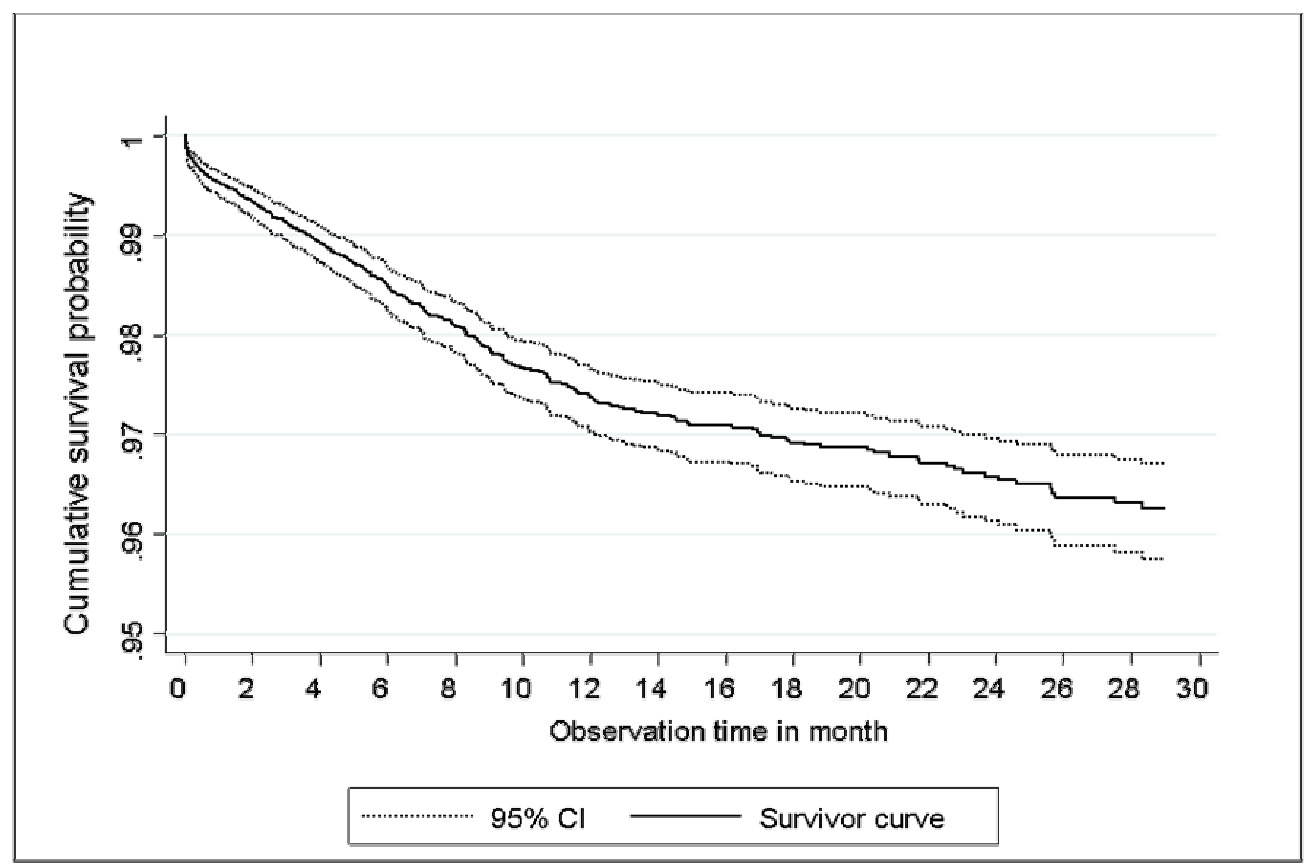

Figure 1. Kaplan Meier survival estimate of study participant over the observation period

To assess the mortality risk at particular points of time during the observation period we calculated the hazard rate which is defined by dividing the total number of deaths by the sum of the observed survival for a particular month. These rates are plotted in Figure 2. The average hazard rate for dying was 0.00178 . We observed a peak of the rate approaching 0.003 in the second month. In month three there was a decrease, though the rate remained above 0.002 until month nine. From this month there was a significant decrease of mortality until month 20 where the rate is below 0.001 . A slight increase was then observed but the rate remained below 0.001 until the end of the observation period interrupted by a small peak in month 25 . 


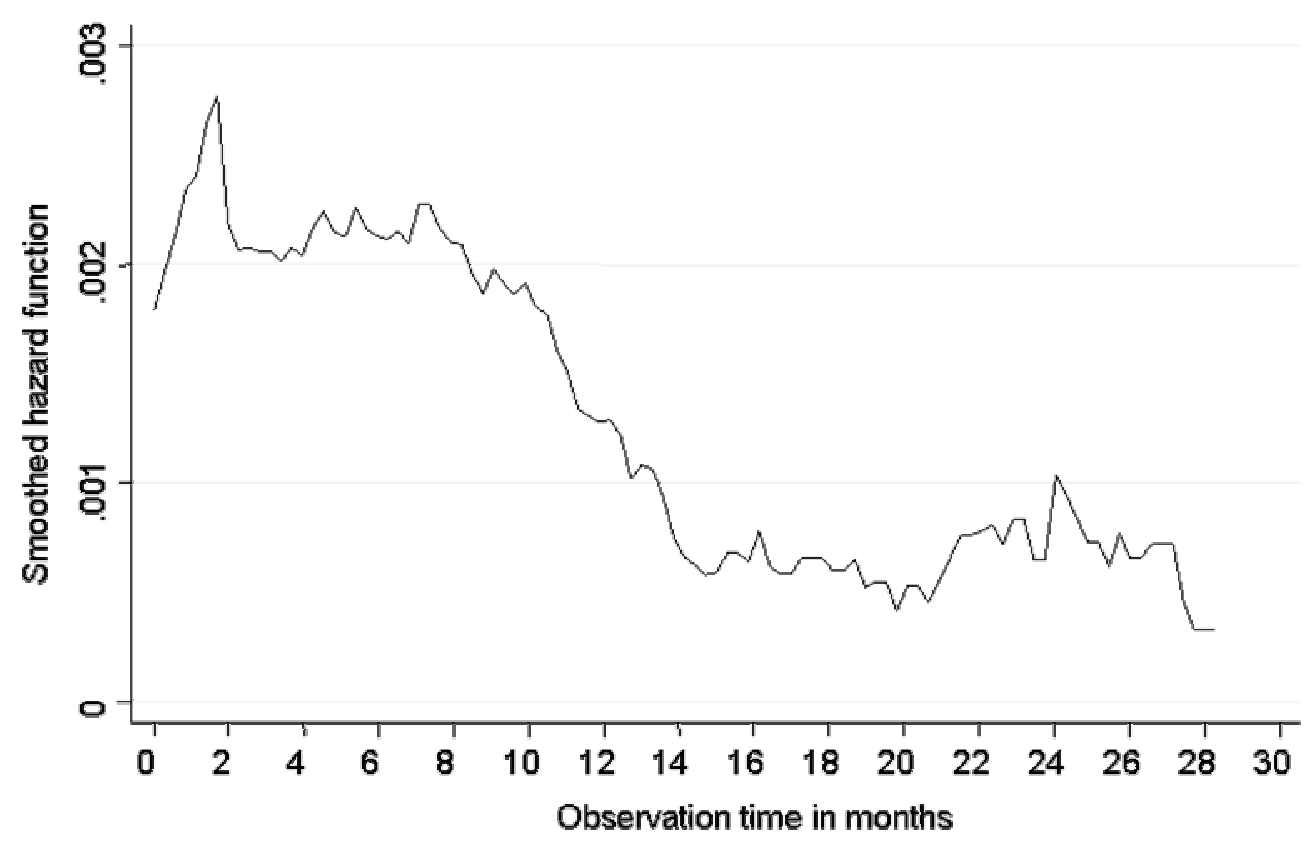

Figure 2. Hazard rate graph of study participant over the observation period

\section{Site and sex specific survival probability}

Figure 3 depicts the sex specific survival probability in each informal settlement. We observed that for both sexes the survival probability is lower in Korogocho than in Viwandani. Indeed, after 12 months of observation the survival probabilities in Viwandani for both sex was above or equal 0.98, while in Korogocho they were below 0.97. At the end of the observation period about $96 \%$ female and $94 \%$ of male survived in Korogocho. The proportion was higher in Viwandani (98\% for females and $97 \%$ for males). In both settlements females have better survival compared to male throughout the observation period. However during month six to nine in Korogocho the survival probability was the same for males and females. 

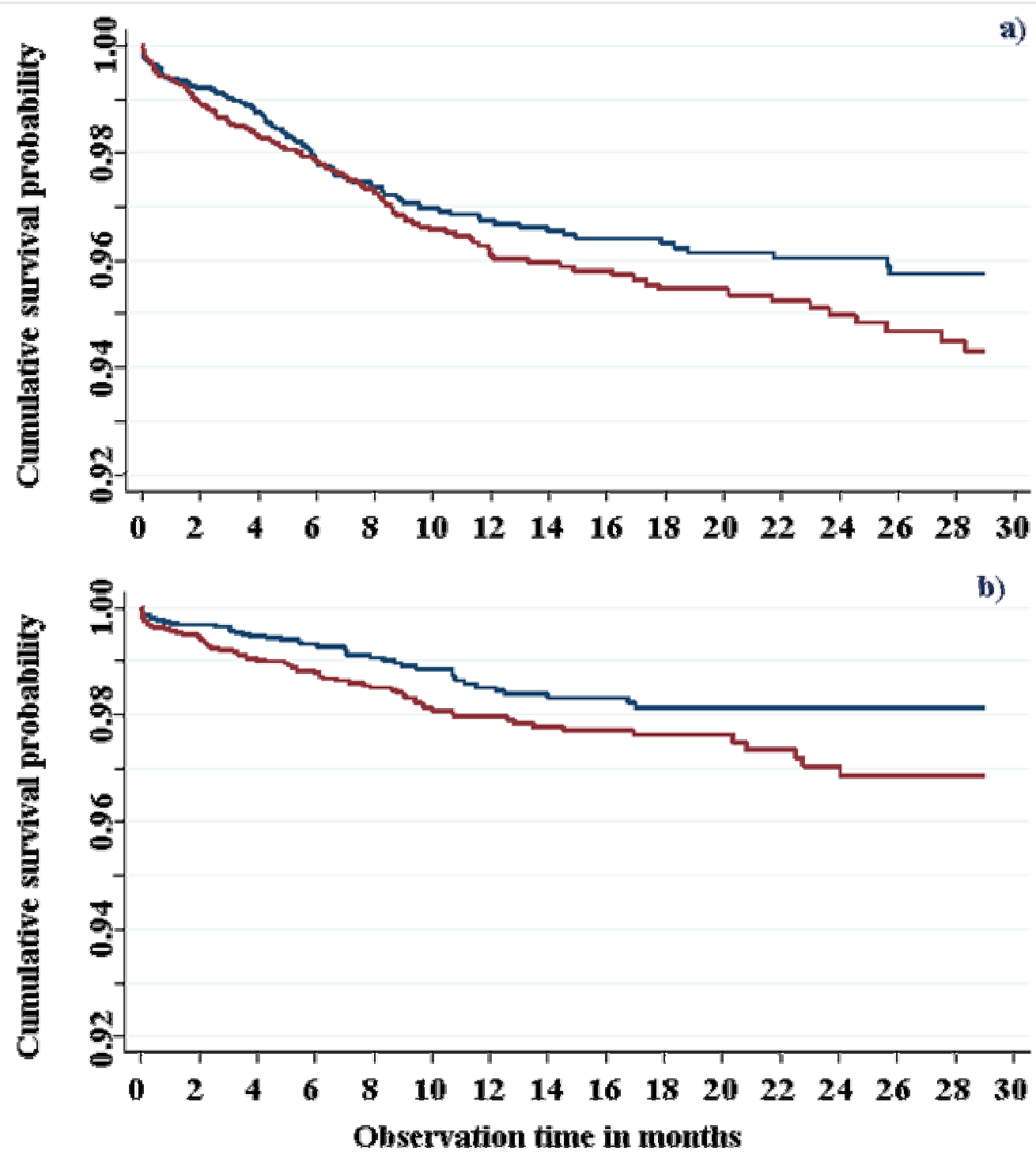

Female Male

Figure 3 Site and sex specifics Kaplan Meier survival estimate of study participants over the observation period: a)Korogocho, b) Viwandani

Cox proportional hazards model: assessing the effect of mothers' migration status on childhood mortality

\section{Testing the Proportional hazards assumption}

Before running the Cox proportional hazards regression model, we first tested for the proportional hazards assumption by comparing the cumulative hazard for children from non migrant mothers to those from migrant mothers over the observation period. We used the graphical methods: As shown in figure 4, the proportionality assumption was not 
rejected since the cumulative hazard curves for the two groups of children remain parallel over the observation period.

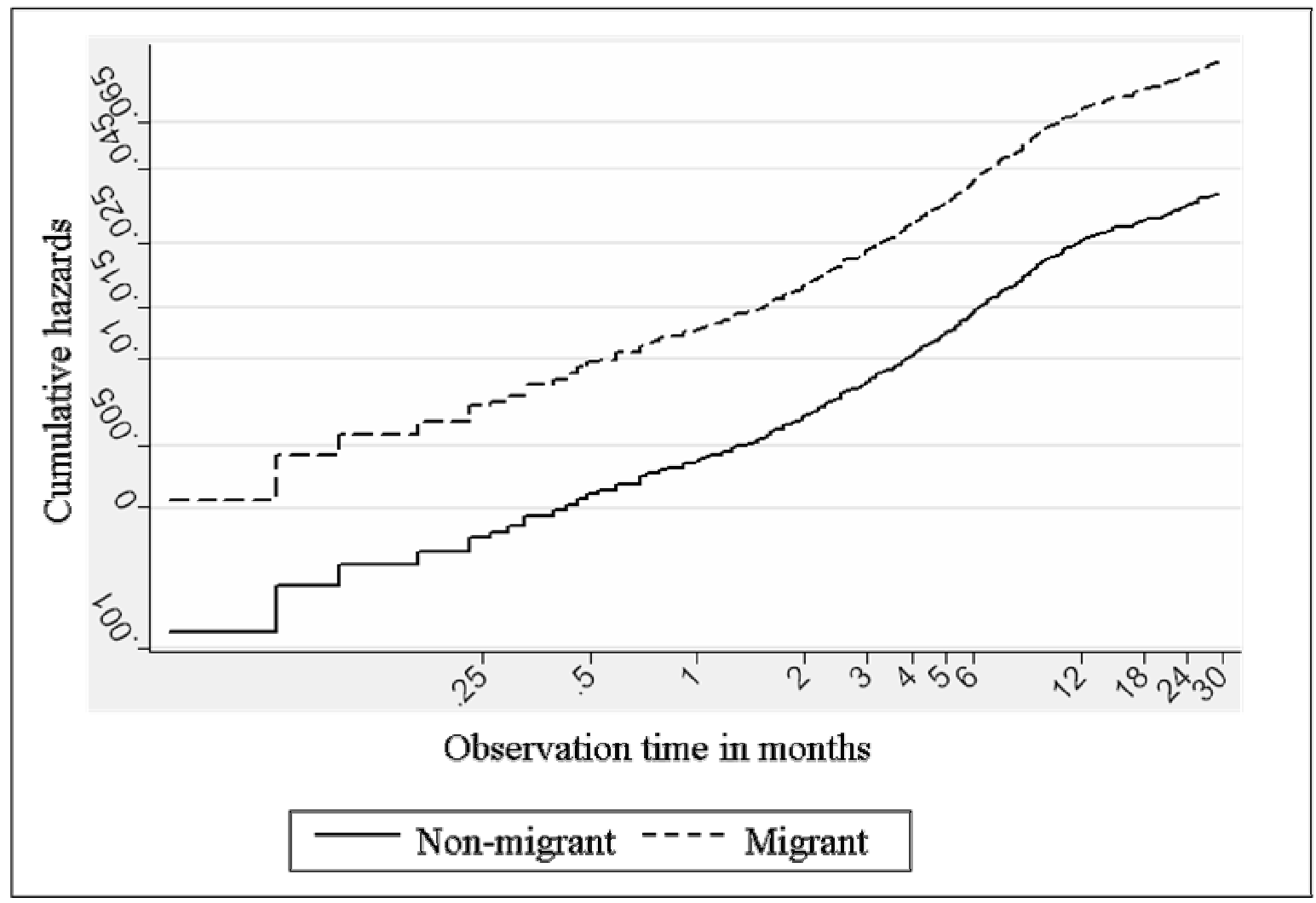

Figure 4: Cumulative hazard test for proportionality assumption

\section{Cox regression model}

We ran several models by progressively adding new covariates in the model. The list of all variables and their description are presented in table 4 . The results of the models including multivariate Cox models are presented in table 5. In general the model goodness of fit got better with increasing number of co-variables. Model 4 which includes all the available co-variables appears to have the best fit (log likelihood= 22234.97) compared to the other three (Model $1=-2877.36$, model $2=-2600.08$ and model $3=2405.55)$. In general, the direction of the effect of the factors considered was maintained in most of the models; except that in model 2 the effect of mother's migration status on childhood survival was not significant. The hazard ratio was 0.8, (95\% CI 0.551.35). This is understandable since the effect was probably confounded by several factors which were taken care of in the model 3 and 4 . Model 1 (bivariate effect) shows much higher effect of the migration status of mother on the risk of childhood mortality (HR $=2.83$, 95\% CI: $1.82-4.43$ ) compared to model 3 (HR=1.83, 95\%CI: 1.15-2.9) and model 4 (HR=1.76, 95\% CI: 1.10-2.81). In all these models children from migrant mothers have worse survival compared to those from non-migrant mothers. According to model 4 they have a hazard ratio of 1.76 (95\% CI: 1.10-2.81), suggesting an increase mortality risk of $76 \%$ compared to children from non-migrant mothers. This mortality risk is not affected by the duration of stay of the mothers (Model 4: HR=1.00, 95\% CI:1.00-1.00). 
The investigations of other co-variables show that gender, age of the child, ethnicity, site of residence, age of the mother, death of the mother, and time specific effects (year of data collection) have significant effects on childhood survival. Females experienced better survival compared to males (model 4: HR=0.79, 95\% CI: 0.62-0.99). With increasing age of the child survival is better. Over the observation period it was associated with $14 \%$ of reduction of mortality (model $4 \mathrm{HR}=0.86$, 95\% CI $0.84-0.87$ ). Children from Korogocho have higher mortality compared to those in Viwandani. They experience 50\% higher mortality (model 4: RR=1.50, 95\% CI 1.14-2.00). Ethnicity was shown to be strongly associated with child mortality. However, the comparison of the individual ethnic group with the Kikuyu (most prevalent) shows that only Luhya and Luo experience significantly higher childhood mortality (model 4: HR=1.55, 95\% CI: 1.062.26, and HR=2.39, 95\%CI: 1.71-3.32, respectively). For the other groups although the risk was different compared to the kikuyu group, the estimates did not reach statistical significance. Increasing age of the mother had an impact on childhood survival of borderline significance (model $4 \mathrm{HR}$ : 1.02, 95\% CI 1.00-1.04). A strong effect of mother's death on childhood mortality was observed (model 3, HR=4.58, 95\% CI 1.1218.57). The results suggest that children who lose their mother have 3.5 times higher mortality compared to those who have their mothers. The education of the mother was not associated with risk of mortality (model 4 : HR $=0.99,95 \%$ CI: 0.94-1.03). The year of data collection appears to be highly associated with an increase risk of mortality. Higher mortality was observed in years 2002 and 2003 compared to year 2004. The HR (model 4) were 19.31 (95\% CI 12.46-29.93) and 6.38 (95\% CI 4.86-8.37) respectively. The results suggest that extremely high mortality was observed in year 2002. 
Table 4. List of variables included the Cox-regression models

\begin{tabular}{|c|c|c|c|}
\hline Variable & Description & Type & Possible values \\
\hline \multicolumn{4}{|l|}{ Outcome } \\
\hline Death & $\begin{array}{l}\text { Death of a participant during the } \\
\text { observation period }\end{array}$ & Binary & $\begin{array}{l}\text { Dead }=1 \\
\text { Not dead }=0\end{array}$ \\
\hline \multicolumn{4}{|l|}{ Explanatory } \\
\hline Migration & $\begin{array}{l}\text { The migration status of the } \\
\text { mother, whether the child was } \\
\text { born after the mother migrated in } \\
\text { the slum or not }\end{array}$ & Binary & $\begin{array}{l}\text { No=0 (ref) } \\
\text { Yes }=1\end{array}$ \\
\hline \multicolumn{4}{|l|}{ Covariables } \\
\hline Gender & The sex of the child & Categorical & $\begin{array}{l}\text { Male }=0 \text { (ref) } \\
\text { Female }=1\end{array}$ \\
\hline Age & The age of the child in months & Continuous & 0-59 month \\
\hline Location & Settlement where the child lives & Binary & $\begin{array}{l}\text { Viwandani }=0 \text { (ref) } \\
\text { Koroogcho }=1\end{array}$ \\
\hline Age of mother & Age of the mother at child birth & Continuous & \\
\hline Ethnicity & Ethnicity of the child & Categorical & $\begin{array}{l}\text { KIK=Kikuyu (ref) } \\
\text { EMB=Embu } \\
\text { KAM=Kamba } \\
\text { KIS=Kisii } \\
\text { LUH=Luhya } \\
\text { LUH=Luo } \\
\text { SOM=Somali } \\
\text { SWA=Swahili }\end{array}$ \\
\hline Year & $\begin{array}{l}\text { The year in which the data was } \\
\text { collected }\end{array}$ & Categorical & $\begin{array}{l}\text { Year2002 } \\
\text { Year2003 } \\
\text { Year } 2004 \text { (ref) }\end{array}$ \\
\hline Length of stay & $\begin{array}{l}\text { The length of stay of the mother } \\
\text { in the slum }\end{array}$ & Continuous & In year \\
\hline Dead of mother & Whether the mother is alive or not & Binary & $\begin{array}{l}\text { Dead }=1 \\
\text { Not dead }=0\end{array}$ \\
\hline Education & $\begin{array}{l}\text { The education level of the month, } \\
\text { in terms of number of years of } \\
\text { school completed }\end{array}$ & Continuous & 1 to 16 years \\
\hline
\end{tabular}


Table 5. Cox proportional hazard regress models out put test for the migration status of the mother on child hood mortality

\begin{tabular}{lcccc} 
& Model 1 & Model 2 & Model 3 & Model 4 \\
\cline { 2 - 5 } Variables & HR (95\% CI) & HR (95\% CI) & HR (95\% CI) & HR (95\% CI) \\
\hline
\end{tabular}

\section{Explanatory}

Migration

No

Yes

\section{Co-variables}

Gender

Male

Female

Age of the child

Slum

Viwandani

Korogocho

Ethnicity

Kikuyu

Embu

Kamba

Kisii

Luhya

Luo

Somali

Year of data collection 2004

2002

2003

Death of the mother

No

Yes

Age of the mother

Education of the mother

Length of stay of mother
$1 \quad 1$

2.83 (1.82-4.43) $0.86(0.55-1.35)$

1

0.80 (0.64-1.00)

0.87 (0.85-0.88)

0.77 (0.61-0.96)

$0.87(0.86-0.89)$

0.79 (0.62-0.99)

$0.86(0.84-0.87)$

1

$1.64(1.26-2.14)$

1

$2.72(0.85-8.74)$

$0.77(0.49-1.21)$

$1.42(0.73-2.76)$

1.47 (1.02-2.11)

2.31 (1.68-3.16)

$0.90(0.38-2.11)$

1

20.07(13.23-30.45)

$6.04(4.63-7.87)$

19.31 (12.46-29.93)

6.38 (4.86-8.37)

1

4.58 (1.12-18.57)

1.02 (1.00-1.04)

$\begin{array}{ll}- & 0.99(0.94-1.03) \\ - & 1.00(1.00-1.00)\end{array}$

$\begin{array}{ll}- & 0.99(0.94-1.03) \\ - & 1.00(1.00-1.00)\end{array}$

$1.95(0.47-8.04)$

0.74 (0.46-1.19)

$1.48(0.75-2.89)$

1.55 (1.06-2.26)

2.39 (1.71-3.32)

$0.86(0.36-2.05)$

1

Log likelihooh

$-2877.36$

$-2600.08$

$-2405.55$

$-2234.97$

* Hazard Ratio, ** 95\% Confidence Interval, bold =significant effect. 


\section{Discussion}

\section{Childhood mortality patterns}

A number of studies have assessed the risk of infant and childhood mortality and associated risk factors (Ouoba 1998, Gyimah 2002, Mboup 2001). However, these studies are most of the time based on DHS data, known to be less appropriate for time series analysis. There are very few studies which are based on longitudinal data with time varying factors (Becher et al 2004). These studies are based on rural settings and the risk factors assessed rarely include migration. In the present study we used event history data analysis techniques to assess the risk of childhood mortality among a population living in urban informal settlements, based on a rich longitudinal DSS data that contains time dependent co-variables. The main focus was the effect of the mother migration status on the risk of childhood mortality.

Our findings demonstrated a decrease of childhood mortality over the three-year observation period. This is in line with the overall trends of mortality in SSA Africa (Garenne and Gakusi 2006). However, the period of observation is too short to draw any conclusions regarding the trend of mortality in the two informal settlements (Korogocho and Viwandani). Nevertheless, there is a significant difference in mortality risk between the three years of observation. The survival probability decreases faster in the first year then slows down until the end of the observation. This is probably driven by the infant mortality known to be high as portrayed in Figure 2 and the fact that the population is getting older. There are also anecdotal reports of an outbreak in 2002 and 2003 in one of the slums resulting in a large number of infant deaths. Unnatural reasons such as changes in data collection procedures over time cannot totally be ruled out. We were able to control for these time specific effects (data collection patterns and disease outbreak) through inclusion of year dummies in the model.

\section{Migration and other risk factors of childhood mortality}

There is clear evidence from our findings that migration is a risk factor for childhood mortality. Indeed our result shows that children from migrant mothers have higher (76\%) mortality compared to those from resident mothers. This situation could be explained by living conditions in the slum to which the incoming children are not yet adapted on one hand. On the other hand the mothers may not yet be integrated into the new environment and may not know how and where to seek health care services if their children need them. Kiros and white (2004) reported low vaccination coverage among children from migrant mothers compared to those from non-migrant and explained these differences by the integration level of the mother in the host community. Considering the integration factors of the mother and the adaptation of child to the new condition we would expect the difference in mortality risk between non-migrant and migrant child to disappear with the duration of stay. Our analysis however did not confirm this hypothesis as the length of stay of the mother did not affect the childhood mortality risk. Similar findings were also reported by Kiros and white, 2004. They did not find a significant effect of the duration of stay of the mother on the vaccination status of their children. This is even 
more so in Kenya where notwithstanding its duration of stay, a migrant mother will always be seen as a stranger and therefore never get fully integrated.

We have also identified other major risk factors associated with childhood mortality in the slum. Sex was shown to be significantly associated with childhood mortality whereby females have lower mortality compared to males. These differences cannot be explained by biological reasons as these findings are in disagreement with other studies who found no difference (Becher et al 2004, CIA 2002, CDC 2001). The reason could be explained by the gender specific conditions of the slums.

Our findings confirmed that older children survive better than younger ones and that overall childhood mortality is mainly driven by infant mortality. The place of residence appears to be a risk factor for childhood mortality whereby children living in Korogocho have 50\% higher mortality risk compared to those living in Viwandani. The higher mortality in Korogocho could be explained by the type of settlement. Korogocho is mainly populated by long term settlers compared to Viwandani which is located next to an industrial area and is populated by temporal labor migrants. This situation may lead to selection bias, whereby people migrating to Viwandani are less likely to come with their families and if they do the children may experience better health due to slightly better access to heath facilities. The temporality of residence also implies higher loss to follow up in the case of Viwandani. Therefore we could not rule out a "healthy migrant effect" in this case (Marmot 1994). I would love to have more explanation here for my own need. On the other hand the differences could be explained by the disease outbreak in the former which occurred in 2003 - the same year that accounts for much of the mortality. The way we dealt with these probable biases was to control for infant age indicator as well as indicator of being born in the slum.

The observed association between childhood mortality and ethnicity demonstrated the difference of mortality risk in a given population, likely to be explained by genetic, cultural, educational, socioeconomic, and environmental differences (Blacker 1991). The higher mortality among Luo and Luhya compared to Kikuyu could be explained by the fact that the Kikuyu group is from the Nairobi region while the others come from different regions of the country. Kikuyu children are therefore better adapted to the conditions, especially the cold climate which may increase the risk of contracting pneumonia - one of the major killers in Kenya (WHO 2006). Ethnic group differences in mortality risk have also been reported in other studies (Blacker 1991, Becher et al 2004).

The age of the mother at child birth plays a significant role in childhood mortality. Children from older mother have better survival compared to those from younger ones. However the difference was very small. Nevertheless, this difference could be explained by older mothers being more experienced in taking care of their children compared to younger ones. The age of the mothers was included in the model as a continuous variable and therefore the effect observed is for an increase of one unit of age in years assuming that the relationship is linear.

The education of the mother was not associated with mortality risk which was rather surprising given the long established relationship between education status and mortality. This result could be attributable to the little variation of the mothers' education level in 
the slums. The education data being used were collected for all mothers at their first observation date in the study area and consequently is not a time varying covariate. The percentage of women with an education is $94.95 \%$ in the two sites combined.

Another major risk factor for childhood mortality is the death of the mother. This factor was highly associated with an increase risk of mortality. Similar findings have been seen in other studies (Koblinsky et al 1994, Becher et al 2004). The death of the mother was considered only if it occurred during the observation time for the child. Children who lose their mother are likely to be exposed to several factors that can increase their mortality risk. These factors could be reduction of care, no breastfeeding, and improper bottle feeding. Due to the HIV/AIDS epidemic an increasing number of children are experiencing the death of their mother and so the impact on childhood mortality will be substantial.

\section{Limitations}

Data from our two urban informal settlements cannot be assumed to representative of all the other informal settlements given that there is a significant variation between the two settlements. However there is no reason to assume that the health risks experiences by all urban informal settlers are different. Therefore they probably experience the same childhood mortality levels.

Our data generated from the DSS was appropriate to explore and assess risk factors associated with childhood mortality. However, the period of observation was too short to be able to assess trends in mortality. Additionally, most of the variables included in our model were not time-dependent except age of the child and length of stay of the mothers. We did not adjust for socio-economic variables because data on these are not routinely collected by the DSS. The available socio-economic data were not collected longitudinally and therefore we could not include them in the model. Attempt to include such variables as time invariant characteristics showed little variation among households. Out of all homes under surveillance, 99.4\% have metal roofs (both corrugated and tin/metal sheets); while 1.6\% have access to their own toilet. On the other hand, $5.1 \%$ of the homes have access to their own source of water (either piped into their houses or the compound) while $7.5 \%$ have electricity in their homes. Over half (68.2\%) of the households have radios while only $6.8 \%$ reported to have a television set. Bicycles are found in only $3.4 \%$ of the homes while motorcycle ownership is very minimal $(0.04 \%)$.

Selection bias can not be totally excluded, since due to our short observation period (average observation period of 13.3 months), we do not observe the group of children born from migrant mother beyond their first birthday (table 1). We controlled for this bias by including an indicator variable for slum born as well as an indicator variable for infant. 


\section{Conclusion}

Childhood mortality in the Nairobi informal settlements remains very high, especially among new migrants. Given the high degree of rural urban migration, which is bound to increase in the foreseeable future for most African countries, our study raises critical public health concerns. There is therefore need to increase access to health care for the migrants through the adaptation of child and maternal health care components of the primary health care concept with specific attention to urban informal settlements. A community service could be put in place to identify new migrants and inform them aboutthe available health services. There is also a need for studies to further assess the health status and health care utilization patterns of children from migrant mothers in this setting such as the vaccination coverage and to define ways to improve it if is found to be low. Another topic of interest is to explore the risk factor associated to the mortality among children who have lost their mother. Our study demonstrated also a persistent disadvantage of children born to migrant mothers irrespective the length of stay in the receiving zone.

\section{Acknowledgement}

We would like to acknowledge the contribution of the APHRC's dedicated DSS field workers, team leaders, field supervisors and field coordinators for making sure that the DSS data are regularly collected. We are also grateful to the data entry and management team for processing the data and making it available for the analysis. Especially, we would like to thank Woubalem Zewdu for the remarkable preliminary data cleaning work. We will remain indebted to the DSS population from Korogocho and Viwandani without whom this work would not has been possible. We are very grateful to them from taking their valuable time to respond to our repetitive questions every four months. Last, but not least we acknowledge the generous support to the NUDHSS by funding from the Rockefeller Foundation and Wellcome Trust to whom we express our gratitude.

\section{References}

Amuyunzu-Nyamongo M and Ezeh AC. (2005) A qualitative assessment of social support in urban poor settings of Nairobi. Journal of Poverty. 9: 89-107

APHRC. (2002a) Health and Livelihood needs of residents of informal settlements in Nairobi city. Occasional Study Report No.1. African Population \& Health Research Center, Nairobi Kenya

APHRC. (2002b) Population and health dynamics in Nairobi Informal Settlements. African Population and Health Research Center, Nairobi Kenya.

Becher H, Müller O, Jahn A, Gbangou A, Kynast-Wolf G, Kouyaté B. (2004) Risk factors of infant and child mortality in rural Burkina Faso, Bulletin of World Health Orgaizastion, 82: 265-273 
Blacker JGC (1991) Infant and child mortality: development, environment, and custom. In: Feachem RG, Jameson DT, editors. Disease and mortality in sub- Saharan Africa. Oxford: Oxford University Press

CBS (Central Bureau of Statistics) (2006). Population projections. Available at URL: http://www.cbs.go.ke/, accessed 11.08.2006. Nairobi, Kenya

Center of Disease Control (2001) National Vital Statistics Report 2001;49:41. Available from: URL: http://www.cdc.gov/nchs/fastats/pdf/nvsr49_01t13.pdf

CIA (2002) The World Factbook 2002. Available from: URL: http://www.worldfactsnow.com/factbook/country/Burkina_Faso/

Delaunay V, Etard JF, Preziosi MP, Marra M, and Simondon F. (2001) Decline of infant and child mortality rates in rural Senegal over a 37-year period (1963-1999). International Journal of Epidemiology, 30: 1286-1293

Dodoo FN, Sloan M and Zulu EM (2002) Space, context, and hardship: Socializing children into sexual activity in Kenyan slums, In: Samuel Agyei Mensah and John B. Casterline (eds), Fertility and reproductive health in sub-Saharan Africa: A Collection of Microdemographis Studies. Westport, Conc.:Greenwood Press

Panel on Urban Population Dynamics (2003). Mortality and Morbidity: Is City life Good for your Health? In: Mark R. Montgomery, Richard Stren, Barney Cohen, and Holly E. Reed (eds), Cities Transformed: Demographic Change and Its Implications in the Developing World National Research Council, National Academy of Science, PP 259-299

Foster SO (1995). Potential health impact of immunization. In H Rashad R.Gray and T Boerma (EDS) evaluation of the impact of health interventions. Liege: international Union for Scientific study of population

Garenne M, Gakusi E. (2006) Health transitions in sub-Saharan Africa: overview of mortality trends in children under 5 years old (1950-2000) Bull World Health Organ vol.84no.6

Gyimah SO (2002). Ethnicity and infant mortality in sub-Saharan Africa: The case of Ghana. Discussion Paper No. 02-10. London, Canada, University of Western Ontario: Population Studies Centre; Available from: URL: http:www.ssc.uwo.ca/sociology/popstudies/dp/dp02-10.pdf

Kiros GE, White MJ. (2004) Migration, community context, and child immunization in Ethiopia. Social Science \& Medicine, 59:2603-2616

Klein JP, Moeschberger ML. Survival analysis. New York (NY): Springer; 1997 
Koblinsky MA, Tinker A, Daly P (1994). Programming for safe motherhood: a guide to action, Health Policy and Planning 9:252-66.

Magadi MA, Zulu EM, and Brockerhoff M. (2003) The inequality of Maternal health care in urban sub-Saharan Africa in the 1990s. Population Studies 57: 347-366

Marmot MG, Adelstein AM, Bulusu L (1994). Lessons from the study of immigrant mortality. Lancet 1:1455-1457

Mboup G (2001) Mortality of children under five years of age. [Mortalité des enfants de moins de cinc ans. In: Republique du Benin Enquete Demographique et de Sante, Benin. Calverton (MD): Demographic Health Surveys; 115-24. Available from: URL: http://www.measuredhs.com/start.cfm

McGranahan G and Songsore J (1994) Weath, health and the Urban household: Weighing Environmental Burden in Accra, Jakarta and Sao Paulo. Environment, 36: 41

McGranahan G. and Songsore J. (1994) Wealth, Health and the Urban Household: Weighing Environmental Burdens in Accra, Jakarta and Sao Paulo,” Environment, Vol. 36: 40-45

Mugisha F, J. Arinaitwe-Mugisha and B. Hagembe (2003) Alcohol, substance and drug use among urban slum adolescents in Nairobi, Kenya. Cities, 20: 231-240.

Nyarko P, Pence B, Debpuur C (2001) Immunization status and child survival in rural Ghana. Population Research division working Paper N0 147, Population Council, New York

Nyarko, P., Pence, B., \& Debpuur, C. (2001). Immunization status and child survival in rural Ghana. Population Research Division Working Paper No. 147, Population Council,New York

Ouoba P (1998) Mortality of children under five years of age. [Mortalité des enfants de moins de cinq ans]. In: Enquete Demographique et de Sante, Burkina Faso. Calverton (MD): Demographic Health Surveys; 1998:135-44. In French. Available from: URL: http://www.measuredhs.com/start.cfm

Pison G, Trape JF, Lefebvre M, Enel C (1993) Rapid decline in child mortality in a rural area of Senegal. International Journal of Epidemiology 1993;22:72-80.

Taffa N, (2003). A comparison of pregnancy and child health outcomes between teenage and adult mothers in the slums of Nairobi, Kenya. International Journal of Adolescent Medical Health, 15: 321-329

UNCHS/Habitat (1992) "The Role of Human Settlements in Improving Community Health in Africa," International Conference on Community Health in Africa, Brazzaville, Congo, 4-6 September 
Valsecchi MG, Silvestri D, Sasieni P. (1996) Evaluation of long-term survival: use of diagnostics and robust estimators with Cox's proportional hazards model. Statistics in Medicine, 15:2763-80

Zulu EM, Dodoo FN, and Ezeh AC (2002) Sexual risk-taking in the slums of Nairobi, Kenya, 1993-1998. Population Studies, 56: 311-323

Zulu EM, Konseiga A, Darteh E, and Mberu B. (2006) Migration and the Urbanization of Poverty in sub-Saharan Africa: The Case of Nairobi City, Kenya. Paper presented at the Population Association of America Annual Meeting, Los Angeles, March 30April 1, 2006 [Session: Migration in Developing Countries] 